\title{
EGF Positively Regulates the Proliferation and Migration, and Negatively Regulates the Myofibroblast Differentiation of Periodontal Ligament-Derived Endothelial Progenitor Cells through MEK/ERK- and JNK-Dependent Signals
}

\author{
Hitomichi Kimuraa,b,c Naoto Okubo ${ }^{a, c, d}$ Naoyuki Chosa ${ }^{a}$ Seiko Kyakumoto \\ Masaharu Kamo ${ }^{a}$ Hiroyuki Miurab ${ }^{b}$ Akira Ishisaki ${ }^{a}$ \\ aDivision of Cellular Biosignal Sciences, Department of Biochemistry, Iwate Medical University, \\ Shiwa-gun, ${ }^{b}$ Division of Orthodontics, Department of Developmental Oral Health Science, School of \\ Dentistry, Iwate Medical University, Morioka, 'These authors contributed equally to this work, ${ }^{d}$ Present \\ address: Department of Pathophysiology and Therapeutics, Division of Pharmasciences, Faculty of \\ Pharmaceutical Sciences, Hokkaido University, Sapporo, Japan
}

\section{Key Words}

Epidermal growth factor • Differentiation • Endothelial progenitor cells • Migration • Mitogen activated protein kinase $\cdot$ Myofibroblast $\cdot$ Periodontal ligament

\begin{abstract}
Background/Aims: Remodeling of fibrous and vascular tissues in the periodontal ligament $(\mathrm{PDL})$ around the tooth root was observed during tooth movement by orthodontic force application. We previously demonstrated that a single cell-derived culture (SCDC) of primarily cultured PDL fibroblasts, called SCDC2, has an endothelial progenitor cell (EPC)-like character and can form endothelial cell (EC) marker-positive blood vessel-like structures. However, the types of molecular mechanisms that control the in vivo kinetic properties and the differentiation of the PDL-derived EPC-like cells into myofibroblasts (MFs), which are known to expand fibrous tissues, require clarification. Methods: Using specific mitogen activated protein kinase (MAPK) inhibitors, we examined how epidermal growth factor (EGF)-mediated MAPK signals affected the proliferation, migration, and MF differentiation of these cells. Results: EGF induced SCDC2 cell proliferation in MAPK/extracellular signal-regulated kinase (ERK) kinase (MEK)- and c-Jun $\mathrm{N}$-terminal kinase (JNK)-dependent manners. In addition, EGF suppressed the expression of MF differentiation markers in these cells in a MEK/ERK-dependent manner, and, moreover, stimulated the cell migration in a MEK/ERK-dependent manner. Conclusion: EGF regulates fibrous tissue remodeling in PDLs through MEK/ERK- and JNK-mediated signals by affecting the proliferation, migration, and MF differentiation of the PDL-derived EPC-like cells.
\end{abstract}

Copyright $@ 2013$ S. Karger AG, Basel 


\section{Introduction}

Ligaments consist of soft connective tissues that transmit mechanical force between bone and bone or bone and muscle. The periodontal ligament (PDL) is a fibrous connective tissue located between the tooth root and the alveolar bone. PDL is composed of various types of cells, including fibroblasts, cementoblasts, osteoblasts, epithelial cells (rests of Malassez), vascular endothelial cells (ECs), and nerve cells [1]. In response to oral environmental alterations such as a tooth movement during orthodontic treatment, the PDL cells have the ability to remodel or reconstruct the periodontal tissue. For PDL tissue remodeling, multipotent progenitor cells or stem cell-like cells must be present in the PDL. Recently, several studies have demonstrated that PDL fibroblastic cells exhibit biological characteristics similar to that of bone marrow-derived undifferentiated mesenchymal cells, suggesting that the mineralized tissue lineages may have originated from a common early progenitor [2-5]. Seo et al. also showed that the PDL cells exhibit cementoblastic/osteoblastic or adipogenic differentiation in vitro and have the potential to generate cementum/PDL-like tissue in vivo, suggesting that multipotent stem cells are present in PDL [6].

We previously demonstrated that several single cell-derived cultures (SCDCs) from a primary culture of rat fibroblast-like cells derived from the PDL expressed EC-specific markers in addition to mesenchymal stem cell (MSC)- and ligament cell-specific markers [7]. Intriguingly, SCDC2 cells, which abundantly expressed the EC marker Tie-2, vigorously constructed blood vessel structures in a three-dimensional type I collagen scaffold, suggesting that SCDC2 cells retain endothelial progenitor cell (EPC)-like characteristics. In addition, SCDC2 cells expressed not only the EC markers Tie-2, von Willebrand factor (vWF), and CD31 but also the myofibroblast (MF) markers alpha-smooth muscle actin ( $\alpha$-SMA), h1calponin, and collagen type I alpha 1 (coll $\alpha 1$ ) $[7,8]$, which suggests that SCDC2 cells may possess MF-like characteristics, which allow them to participate in remodeling of fibrous tissue networks in PDL tissue. MFs are known to arise from undifferentiated mesenchymal cells and are responsible for collagen turnover at the site of fibrous tissue remodeling [reviewed in 9]: MF expands fibrous tissue by the formation of the collagen network. Meng et al. demonstrated that orthodontic mechanical tension affected the expression of $\alpha$-SMA by PDL-derived fibroblast-like cells [10]: fluorescent immunohistochemical analysis revealed that the expression of $\alpha$-SMA was induced in the tensed side of the PDL by unidirectional orthodontic force loading on the tooth, suggesting that PDL fibroblasts retain the potential to differentiate into MF in response to mechanical loading. However, the molecular mechanisms underlying the orthodontic force-induced expression of MF markers in the PDL-derived EPClike cells still require clarification.

Epidermal growth factor (EGF) was first purified from the mouse salivary gland as a soluble factor that accelerates wound healing in the cornea [11]; however, EGF was soon found to be a general growth factor that regulates various cellular functions involving cell proliferation and differentiation [reviewed in 12,13]. The EGF receptor (EGFR) family consists of four receptors: EGFR (ErbB-1/HER-1), ErbB-2 (HER-2/neu), ErbB-3 (HER-3), and ErbB-4 (HER-4) [14]. ErbB-2 lacks the ability to bind to ligands, whereas ErbB-3 lacks the intrinsic kinase activity; thus, ErbB-2 and ErbB-3 are non-autonomous. However, ErbB2 or ErbB-3 form heterodimeric complexes with other ErbB receptors, which are able to generate potent intracellular signals [reviewed in 15]. EGF binds to EGFR and exert the dimerization of the receptors. Then, the cytoplasmic tyrosine kinase domains of EGFR can be autophosphorylated to mediate intracellular signals to various signaling proteins. The carboxy terminal tyrosine residues on EGFR, Tyr1068 and Tyr1173, are the major sites of autophosphorylation, which occurs as a result of EGF-binding and transduces the EGFinduced signals $[16,17]$. Intracellular signaling downstream of the autophosphorylated EGFR results in the activation of phospholipase $\mathrm{C} \gamma$ (PLC $\gamma$ ) and the downstream calcium- and protein kinase $\mathrm{C}$ (PKC)-mediated cascades, mitogen activated protein kinases (MAPKs) such as extracellular signal-regulated kinase (ERK), c-Jun N-terminal kinase (JNK), and p38 MAPK, small GTPases such as Rho and Rac, multiple signal transducer and activator of transcription 
(STAT) isoforms, heterotrimeric G proteins, phosphatidylinositol 3'-OH kinase (PI3K), and phospholipase D (PLD) [reviewed in 13].

EGF facilitates the ex vivo expansion of bone marrow-derived MSCs (BM-MSCs) while preserving the potential for differentiation [reviewed in 18]. In addition, EGF has an ability to maintain colony-forming potential of BM-MSCs. Thus, EGF enhances the self-renewal of MSCs in vitro, which suggests that this growth factor might play an important role in the enhancement of the therapeutic potential of MSCs. Intriguingly, PDL-derived undifferentiated mesenchymal cells express EGF [19] and EGFR [20]. In addition, Matsuda et al. reported that the EGF/EGFR system acted as a negative regulator of osteoblastic differentiation of the PDL-derived cells, suggesting that EGF affects the differentiation commitment of PDLderived MSC-like cells [20]. However, it remains to be clarified whether the EGF/EGFR system affects the multipotency of PDL-derived undifferentiated mesenchymal cells. On the other hand, Kong et al. reported that EGF positively controls migratory activity of bovine medial collateral ligament-derived fibroblasts [21]. However, it remains to be elucidated what kinds of molecular mechanisms underlie the proliferation, migration, and MF differentiation of the PDL-derived undifferentiated fibroblastic cells. Each MAPK module plays a discrete yet complementary role in cell proliferation, migration, and differentiation in a cell type-specific manner [reviewed in 22, 23]. Here, we evaluate how the EGF-induced MAPKs-mediated signals affect the proliferation, migration, and MF differentiation of PDL-derived EPC-like fibroblastic cells, which is expected to explain the molecular mechanisms underlying the orthodontic force-induced remodeling of fibrous tissue network in PDL.

\section{Materials and Methods}

\section{Reagents}

Recombinant fibroblast growth factor (FGF)-1 was purchased from R\&D Systems Inc. (Minneapolis, MN, USA). Recombinant EGF and transforming growth factor (TGF)- $\beta 1$ were purchased from PEPROTEC Inc. (Rocky Hill, NJ, USA). Kinase inhibitors, namely, the MAPK/ERK kinase (MEK) inhibitor U0126, the JNK inhibitor SP600125, and the EGFR inhibitor PD153035, were purchased from Calbiochem (Merck KGaA, Darmstadt, Germany).

\section{Cell culture}

The isolation of rat PDL fibroblasts and establishment of SCDCs have been previously described [7]. SCDC2 cells were basically cultured on type I collagen-coated plastic dishes (Sumilon Celltight Plate, Sumitomo Bakelite Co., Tokyo, Japan) in Ham's F-12 (Sigma Chemicals, St. Louis, MO, USA) supplemented with $2 \mathrm{mM}$ glutamine (100× solution; Gibco), 10\% fetal bovine serum (FBS; PAA laboratories Inc., Ontario, Canada), $10 \mathrm{ng} / \mathrm{mL}$ FGF-1 (R\&D Systems Inc.), 15 g/mL heparin (Sigma Chemicals Co., Irvine, UK), 100 $\mu \mathrm{g} / \mathrm{mL}$ kanamycin (Meiji Seika Pharma Co. Ltd., Tokyo Japan), penicillin (Gibco, Carlsbad, CA, USA), and streptomycin (Gibco) in a humidified atmosphere of $95 \%$ air and $5 \% \mathrm{CO}_{2}$ at $37^{\circ} \mathrm{C}$. Heparin was added to achieve optimal FGF-1 activity [24]. Subconfluent cells were detached using a trypsin/EDTA solution $(0.05 \%$ trypsin, $0.02 \%$ EDTA; Gibco) and subcultured. Cells from passages 13 to 18 were used in the experiments described below. In experiments with chemical inhibitors, each inhibitor was dissolved in DMSO and added to the culture medium, and the same amount of DMSO $(0.1 \%)$ was added to the control culture.

\section{Cell proliferation assay}

Cellular metabolic activity in SCDC2 cells was evaluated using the Premix WST-1 Cell Proliferation Assay System (Roche Diagnostics, K.K.). This assay is based on the reduction of the tetrazolium salt WST1 [2-(4-Iodophenyl)-3-(4-nitrophenyl)-5-(2,4-disulfophenyl)-2H-tetrazolium] by succinate-tetrazolium reductase to yield colored formazan compounds that are detectable in viable cells. For the WST-1 assay, SCDC2 cells were seeded into 96-well plates at a density of $5 \times 10^{3}$ cells per well and cultured for 3 days in a medium containing 1\% FBS and indicated concentrations of EGF, with or without EGFR-, MEK- or JNK-inhibitors. Then, the medium was replaced with Ham's F-12 containing 10\% Premix WST-1 solution to evaluate the proliferative activity of SCDC2 cells, and the cells were cultured for an additional $4 \mathrm{~h}$. The 
absorbance in each well was measured using a plate reader (Tosoh Corp., Tokyo, Japan). The data were shown as values of $\mathrm{Abs}_{450}-\mathrm{Abs}_{600}$. Each experiment was repeated 3 times, with 6 wells for each time point.

\section{Western blotting of phosphoproteins}

Cells were plated onto standard 9-cm plastic dishes at a density of $5 \times 10^{5}$ cells/dish in Ham's F-12 supplemented with $2 \mathrm{mM}$ glutamine, 10\% FBS, $10 \mathrm{ng} / \mathrm{mL}$ FGF-1, and $15 \mu \mathrm{g} / \mathrm{mL}$ heparin. After 2 days, the growth medium was replaced with Ham's F-12 containing 1\% FBS for serum starvation for 1 day. Then, the cells were cultured for the indicated periods in the medium containing 1\% FBS and various concentrations of EGF with or without EGFR-, MEK- or JNK-inhibitors. Next, the cells were lysed in RIPA buffer [50 mM Tris$\mathrm{HCl}$ (pH 7.2), $150 \mathrm{mM} \mathrm{NaCl}, 1 \% \mathrm{NP}-40,0.5 \%$ sodium deoxycholate, and $0.1 \%$ SDS] containing a protease and phosphatase inhibitor cocktail (Sigma, St. Louis, MO), and then boiled for 5 min. Equivalent amounts of samples were separated by SDS-PAGE using $12.5 \%$ polyacrylamide gels, and proteins were electrotransferred onto PVDF membranes (Millipore Corp., Bedford, MA, USA). The membranes were blocked with a PVDF Blocking Reagent for Can Get Signal ${ }^{\circledR}$ (TOYOBO, Inc., Osaka, Japan) for $2 \mathrm{~h}$ at room temperature and then incubated with primary antibodies overnight at $4^{\circ} \mathrm{C}$. The primary antibodies (rabbit anti-ERK1/2, rabbit anti-p38MAPK, rabbit anti-JNK, rabbit anti-phospho-ERK1/2, rabbit anti-phospho-p38MAPK, and rabbit anti-phospho-JNK polyclonal antibodies), were obtained from Cell Signaling Technology (Beverly, MA, USA). For the detection of EGFR phosphorylation at Tyr1173, a goat anti-phospho-EGFR polyclonal antibody (sc12351) was obtained from Santa Cruz Biotechnology Inc. (San Diego, CA, USA). To detect total amounts of cofilin or cofilin phosphorylated at Ser3, rabbit anti-cofilin (\#5175, Cell Signaling Technology) and rabbit anti-phospho-cofilin (\#3313, Cell Signaling Technology) monoclonal antibodies were used. For the detection of total amounts of c-Jun or phosphorylated c-Jun, rabbit anti-c-Jun (\#9165, Cell Signaling Technology) and rabbit anti-phospho-c-Jun (Ser73) (\#3270, Cell Signaling Technology) monoclonal antibodies were used. After washing with Tris buffered saline (TBS) with Tween 20 (TBS-T: 50 mM Tris-HCl, pH 7.2, 150 mM $\mathrm{NaCl}$, and $0.1 \%$ Tween-20), the membranes were incubated with the appropriate horseradish peroxidaseconjugated anti-mouse, anti-rabbit, or anti-goat secondary antibodies (Santa Cruz Biotechnology, Inc.). The target proteins were washed with TBS-T and detected by enhanced chemiluminescence with the Amersham $^{\mathrm{TM}}$ ECL $^{\mathrm{TM}}$ Western Blotting Analysis System (GE Healthcare, Buckinghamshire, UK). All other conditions and the procedures for each immunoblot with various antibodies were according to the manufacturer's instructions. The detected blots were photographed using the photo image detection system CL-Cube L (Tohoku Electronic Industrial Co., Ltd., Sendai, Japan) and densitometrically measured using Image J (version 1.44). Data were shown as the ratio of the band intensity of the phosphorylated bands to that of the total molecular bands. In some cases, the bands of the reference protein glyceraldehyde-3phosphate dehydrogenase (GAPDH) obtained from whole cell lysates were used as the internal controls for different sample preparations (Fig. 1B). A rabbit anti-GAPDH polyclonal antibody (IMUGENEX, San Diego, CA, USA) was used for the detection of GAPDH.

Quantitative reverse transcriptase-polymerase chain reaction

SCDC2 cells were seeded into 12 -well plates at a density of $7.0 \times 10^{4}$ cells/well in Ham's F-12 containing $5 \%$ FBS and EGF (10 ng/mL), with or without EGFR-, MEK-, or JNK-inhibitors and then cultured for 3 days. In some cases, the cells were first cultured with or without TGF- $\beta 1(1 \mathrm{ng} / \mathrm{mL})$ for 3 days, washed with the Ham's F-12 media 3 times, and then cultured with or without EGF (10 ng/mL) for 3 days (Fig. 4D). Then, total RNA was extracted with the ISOGEN reagent (Nippongene, Tokyo, Japan) according to the manufacturer's instructions. First-strand cDNA was synthesized from total RNA by using the PrimeScript RT Reagent Kit (Takara Bio Inc., Otsu, Japan). Quantitative reverse transcriptase-polymerase chain reaction (qRT-PCR) was performed on a Thermal Cycler Dice Real Time System (Takara Bio Inc.) using SYBR ${ }^{\circ}$ Premix Ex Taq II ${ }^{\mathrm{TM}}$ (Takara Bio Inc.) with specific oligonucleotide primers. The mRNA levels of $\alpha$-SMA, h1-calponin, and colI $\alpha 1$ were normalized to that of the endogenous reference gene $G A P D H$, and were shown as fold increases or decreases relative to the level of the control sample. The primers used were $\alpha$-SMA, $5^{\prime}$-AGC CAG TCG CCA TCA GGA AC-3' (sense) and 5'-CCG GAG CCA TTG TCA CAC AC-3' (antisense); h1-calponin, 5'-ACA CTT TAA CCG AGG TCC TGC CTA-3' (sense) and 5'-CAC GCT GGT CGT ATT TCT G-3' (antisense); coll $\alpha 1$, 5'-AGC TCC TGG GCC TAT CTG ATG A-3' (sense) and 5'-AAT GGT GCT CTG AAA CCC TGA TG-3' (antisense); and GAPDH, 5'-GGC ACA GTC AAG GCT GAG AAT C-3' (sense) and 5'-ATG GTG GTG AAG ACG CCA GTA-3' (antisense). 
Kimura et al.: Effects of EGF on Proliferation, Migration, and Differentiation of Ligament Cells

\section{Immunofluorescence analysis}

For Fig. 3B, SCDC2 cells were seeded in type I collagen-coated 8-chamber slides at a density of $1.4 \times$ $10^{4}$ cells/well in Ham's F-12 containing 5\% FBS and EGF $(10 \mathrm{ng} / \mathrm{mL})$ with or without MEK-inhibitors, and then cultured for 3 days.

For Fig. 4C, the cells were seeded into type I collagen-coated 8-chamber slides at a density of $1.4 \times 10^{4}$ cells/well in Ham's F-12 containing 5\% FBS and cultured for 2 days. Next, in some cases, cells were treated with TGF- $\beta 1(1 \mathrm{ng} / \mathrm{mL})$ for 3 days. Then, the culture media was discarded, and each well was washed 3 times with Ham's F-12 media. Then the cells were further cultured with or without EGF (10 ng/mL) for 3 days.

After the culture procedures described above, the cells on the glass slides were fixed in $4 \%$ paraformaldehyde in phosphate buffered saline (PBS: $135 \mathrm{mM} \mathrm{NaCl}, 1.3 \mathrm{mM} \mathrm{KCl}, 3.2 \mathrm{mM} \mathrm{Na}_{2} \mathrm{HPO}_{4}$, and $0.5 \mathrm{mM} \mathrm{KH}_{2} \mathrm{PO}_{4} ; \mathrm{pH}$ 7.4) for $30 \mathrm{~min}$ and permeabilized with $0.2 \%$ Triton X-100 in PBS for 15 min. The cells were blocked with $2 \%(\mathrm{w} / \mathrm{v})$ bovine serum albumin (BSA) in PBS for $30 \mathrm{~min}$ and then labeled with anti- $\alpha$-SMA rabbit polyclonal antiserum (1:200; Abcam Ltd., Cambridge, UK), anti-h1-calponin rabbit monoclonal antiserum (1:200; Abcam Ltd.), or a rabbit anti-Tie-2 polyclonal antibody (1:50; sc-324, Santa Cruz Biotechnology, Inc.) for $1 \mathrm{~h}$ at room temperature. After washing with PBS, the cells were incubated with an Alexa Fluor ${ }^{\circledR}$ 568-conjugated goat anti-rabbit IgG (1:200; Molecular Probes, Leiden, the Netherlands; Fig. 3B), or Alexa Fluor ${ }^{\circledR}$ 594-conjugated goat anti-rabbit IgG (1:200; Invitrogen, Oregon, USA; Fig. 4C) for $30 \mathrm{~min}$ at room temperature. The cells were washed with PBS and labeled with DAPI (1:1000; KPL Inc., Gaithersburg, MD, USA) and Alexa Fluor ${ }^{\circledR}$ 488-conjugated phalloidin (1:500; Invitrogen, Oregon, USA). Fluorescent signals were detected and photographed using an Olympus IX71 fluorescence microscope equipped with a DP72 digital camera (Olympus Corp., Tokyo, Japan).

Force application against $\beta 1$ integrins on the surface of cultured cells

The force generation model used in this study has been previously described [25, 26]. Magnetite 2.5$\mu \mathrm{m}$ diameter polystyrene beads (Spherotec, Lake Forest, IL, USA) were coated with collagen, as previously reported [27]. The collagen-coated magnetite beads (5-30 $\mu \mathrm{L}$ of the bead stock solution at $1.9 \times 10^{6}$ beads $/ \mu \mathrm{L}$ ) were incubated with $5.0 \times 10^{5}$ cells cultured on plastic tissue culture plates for $60 \mathrm{~min}$, to allow attachment to the $\beta 1$ integrins on the dorsal surface of the cultured cells. Non-coated beads attached to cell surfaces by non-specific interactions were used as the negative control. A ceramic permanent magnet (grade 8, $2.2 \times 9.6 \times 11 \mathrm{~cm}$; Jobmaster, Mississauga, ON, Canada) was used to generate mechanical forces against the beads $\left(0.6 \mathrm{pN} / \mu \mathrm{m}^{2}\right)$ perpendicular to the dorsal surface of the cell. For all experiments, the pole face was parallel to cell culture dish surface and was $2 \mathrm{~cm}$ away from the culture dish surface. As the surface area of the magnet was larger than that of the culture dishes and the beads were uniformly spread over the cells, the forces applied to cells across the width of the culture dish were almost uniform. Constant forces of the indicated duration were used for all experiments. The magnetic force against the collagen-coated beads attached to the cell surface was applied for 60 min (Fig. 4A) or 3 days (Fig. 4B).

\section{Evaluation of proteins associated with collagen-coated magnetic beads}

Proteins that were associated with the collagen beads were collected as previously described [26]. Briefly, the collagen-coated-bead-attached cells were treated with a cytoskeletal extraction buffer $(0.5 \%$ Triton X-100, $50 \mathrm{mM} \mathrm{NaCl}, 300 \mathrm{mM}$ sucrose, $3 \mathrm{mM} \mathrm{MgCl}$, $\mathrm{pH}$ 6.8). Then, the beads in the extraction buffer were collected using a side-pull magnet. Bead-associated cytoskeletal proteins were removed from the beads by boiling them with $100 \mu \mathrm{L}$ of RIPA buffer. Equivalent amounts of the samples were separated by SDS-PAGE, and the separated proteins were electrotransferred onto PVDF membranes. Then, immunoblot analyses were performed with a mouse anti- $\beta$-actin monoclonal antibody (sc-47778, Santa Cruz Biotechnology, Inc.), a rabbit anti- $\beta 1$ integrin polyclonal antibody (sc-8978, Santa Cruz Biotechnology, Inc.), and a rabbit antiGAPDH polyclonal antibody, as described above. Data were shown as the specific bands of collagen-coatedbead-associated proteins and those of the total proteins obtained from the whole cell lysates.

\section{Evaluation of the SCDC2 cell migratory activity}

Boyden chamber migration assays were performed as follows: cells were plated at a density of $2.0 \times$ $10^{4}$ cells in the upper chamber of a Boyden chamber apparatus in Ham's F- 12 media with $0.1 \%$ BSA. Next, the cells were allowed to migrate through the porous membrane that bordered the upper and lower chambers 
into the low chamber, which contained Ham's F-12 media; this process was allowed to occur for $14 \mathrm{~h}$ at $37^{\circ} \mathrm{C}$ in the presence or absence of EGF, the MEK inhibitor U0126, or the JNK inhibitor SP600125 at the indicated concentrations. EGF, U0126, or SP600125 were added to the culture media in both the upper and lower chambers. The membrane was fixed in 4\% paraformaldehyde in PBS and stained using the Diff-Quick stain kit (Sysmex Co., Kobe, Japan) for 2 h. Cells that had migrated onto the underside of the membrane were counted in 9 fields on the membrane, and the value was shown as the average of the 9 fields. The migration of the control was set to $100 \%$, and all other datasets were measured against this value.

\section{Statistical analysis}

Data were presented as mean \pm SD. Differences between treatments were evaluated using Student's $t$-test for single comparisons. The results shown in all experiments were representative of at least 3 separate experiments. A $p$ value of $<0.05$ was considered statistically significant.

\section{Results}

EGFR-mediated signaling stimulates cell proliferation of the PDL-derived EPC-like fibroblastic cells

Cell proliferation was evaluated by the WST-1 assay, as described in Materials and Methods. EGF promotes cell growth in a dose-dependent manner in the concentration range of $0.1-10 \mathrm{ng} / \mathrm{mL}$ (Fig. 1A). In addition, the EGF-induced proliferation of SCDC2 cells was completely inhibited by the addition of the EGFR inhibitor PD153035 [28] at $5 \mu \mathrm{M}$. Next, in order to confirm that EGF activated the EGFR and its downstream molecules in SCDC2 cells, we examined the phosphorylation of EGFR and its downstream molecules ERK, JNK, and p38 MAPK by western blot analyses. SCDC2 cells were stimulated with $10 \mathrm{ng} / \mathrm{mL}$ EGF for the indicated time periods. EGF upregulated phosphorylation of EGFR, ERK, and JNK at $5 \mathrm{~min}$ after EGF stimulation; the phosphorylation peaked at approximately 10-15 min, and then gradually decreased (Fig. 1B, C, and D, respectively). However, EGF had little to no effect on p38 MAPK phosphorylation (Fig. 1E). In order to confirm that PD153035 properly attenuated the EGF-induced signaling at the receptor level, we examined the phosphorylation of the EGFR downstream molecules ERK and JNK after EGF stimulation. PD153035 clearly suppressed the EGF-induced phosphorylation of ERK and JNK (Fig. 1F). These results indicate that EGF signaling through EGFR promotes the proliferation of SCDC2 cells.

EGF-induced MEK/ERK- and JNK-mediated signals positively regulate the proliferation of the PDL-derived EPC-like fibroblastic cells

In order to investigate whether the EGFR downstream molecules ERK and JNK mediate the EGF-induced signaling pathway to enhance proliferation of SCDC2 cells, various specific kinase inhibitors were utilized. The cells were stimulated with EGF $(10 \mathrm{ng} / \mathrm{mL})$ with or without the MEK inhibitor U0126 (1.0-5.0 $\mu \mathrm{M})$ or the JNK inhibitor SP600125 (5.0-10 $\mu \mathrm{M})$, and then the proliferation status was evaluated. As shown in Fig. 2A and B, each inhibitor suppressed the EGF-promoted proliferation in a dose-dependent manner. In addition, U0126 $(5 \mu \mathrm{M})$ or SP600125 $(10 \mu \mathrm{M})$ completely suppressed the EGF-induced enhancement of growth activity (Fig. 2A and B, respectively). In order to confirm that U0126 and SP600125 properly attenuated the EGF-induced signals at the level of MEK and JNK, respectively, we examined phosphorylation of their downstream molecules after treatment with the kinase inhibitors. As shown in Fig. 2C (left panel), U0126 clearly suppressed EGF-induced phosphorylation of the MEK-downstream molecule ERK. In addition, SP600125 clearly suppressed EGF-induced phosphorylation of the JNK-downstream molecule c-Jun at Ser73 (Fig. 2C, right panel).

EGF negatively regulates MF marker expression in the PDL-derived EPC-like fibroblastic cells through MEK/ERK-mediated signals

To investigate whether EGF-activated signals mediated by MEK/ERK affect the expression status of the MF markers in SCDC2 cells, U0126 was added to cell cultures under 


\section{Cellular Physiology Cell Physiol Biochem 2013;32:899-914 and Biochemistry \\ Kimura et al.: Effects of EGF on Proliferation, Migration, and Differentiation of Ligament Cells}

Fig. 1. EGF enhances the proliferative activity and induces EGFR and MAPK phosphorylation in PDL-derived EPC-like fibroblastic cells. (A) SCDC2 cells were treated with EGF at the indicated doses for 3 days. Some of the cells were treated with the EGFR inhibitor PD153035 (5 $\mu \mathrm{M})$. Next, cell growth was evaluated using the WST-1 assay, as described in Materials and Methods. WST-1 working solution [10\% WST-1 in Ham's F-12] was added to each well, and the culture was incubated for $4 \mathrm{~h}$. The absorbance of each well was measured using a plate reader. The data were shown as values of $\mathrm{Abs}_{450}-\mathrm{Abs}_{600}$. Each experiment was repeated 3 times with 6 wells for each point $\left({ }^{*} \mathrm{P}<0.01\right.$; $\left.{ }^{* *} \mathrm{P}<0.05\right)$. (B), (C), (D), and (E) SCDC2 cells were treated with $10 \mathrm{ng} / \mathrm{mL}$ EGF for the indicated times, and then, the phosphorylation status of (B) EGFR, (C) ERK, (D) JNK, and (E) p38 MAPK was evaluated by western blotting with antibodies as described in Materials and Methods. (F) In
A

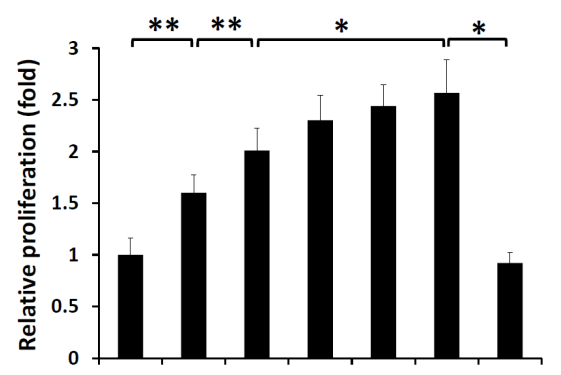

$\mathrm{EGF}(\mathrm{ng} / \mathrm{ml}) \quad-\quad \begin{array}{llllll}0.1 & 0.3 & 1.0 & 3.0 & 10.0 & 10.0\end{array}$ PD153035 $(\mu \mathrm{M})$ - $\quad$ - $\quad-\quad-\quad-\quad-\quad 5$

B

C

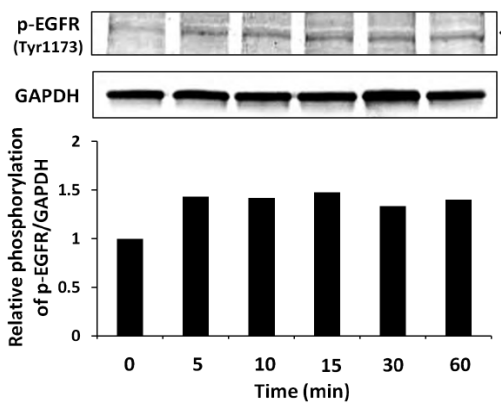

D

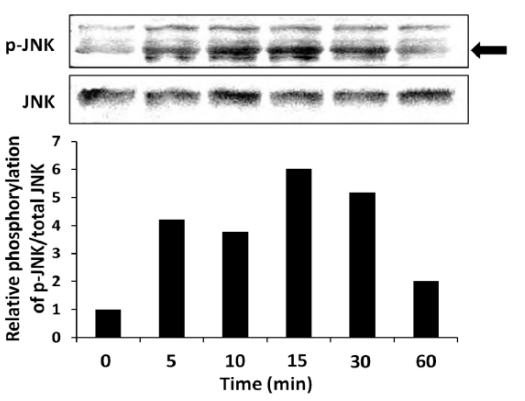

E

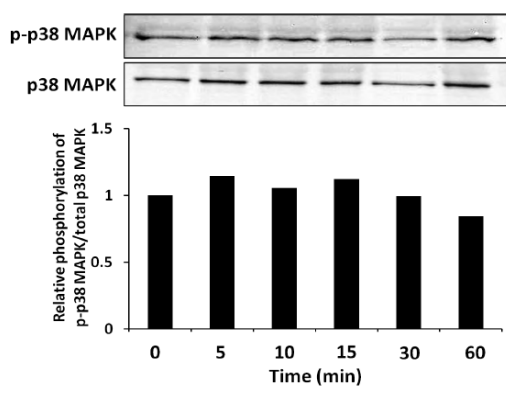

$\mathbf{F}$
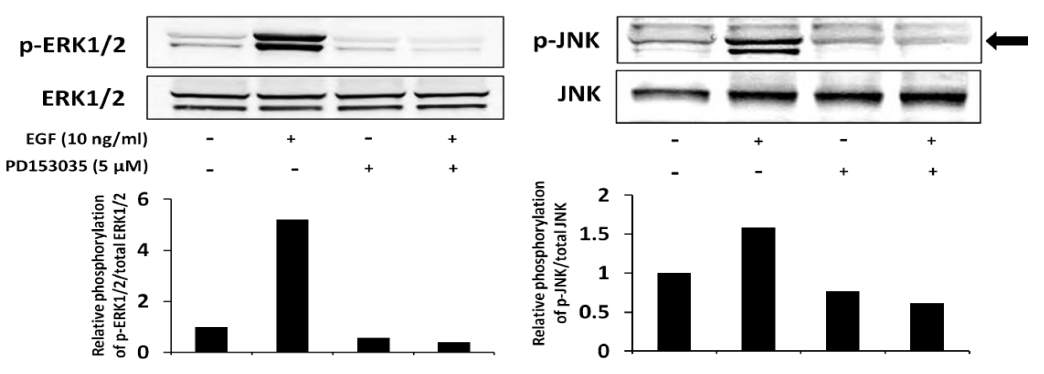

order to confirm that the EGFR inhibitor properly attenuated the EGF-induced ERK- or JNK-activities, phosphorylation of these MAPKs were evaluated in EGF-treated SCDC2 cells with or without PD153035 (5 $\mu$ M) by western blotting, as described above.

stimulation with EGF; the mRNA and protein expression of MF-specific markers were then evaluated by qRT-PCR and immunocytochemical analyses, respectively. As shown in Fig. 3A, U0126 treatment (at the concentration range of 1-5 $\mu \mathrm{M}$ ) clearly increased the mRNA level of 


\section{Cellular Physiology $\quad$ Cell Physiol Biochem 2013;32:899-914 \\ and Biochemistry

A

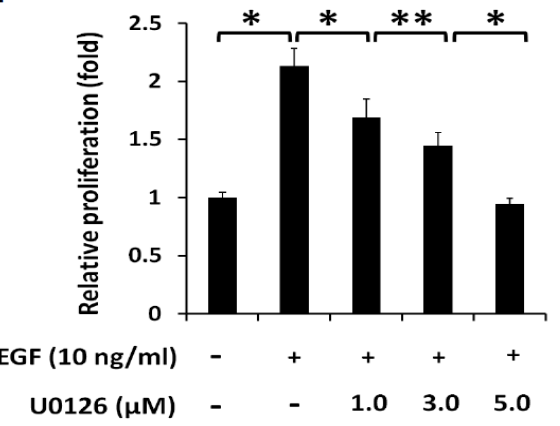

C
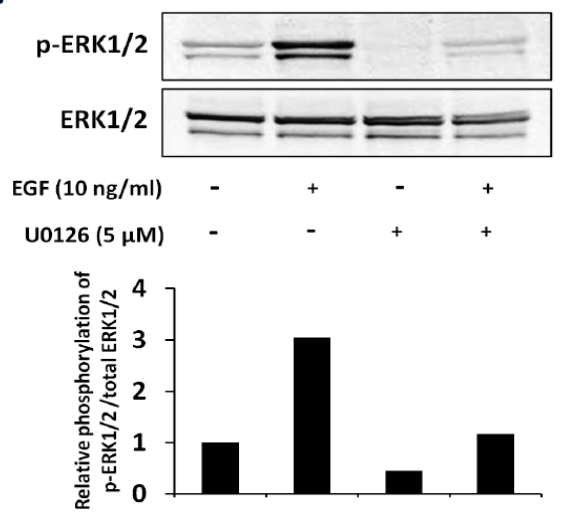

B
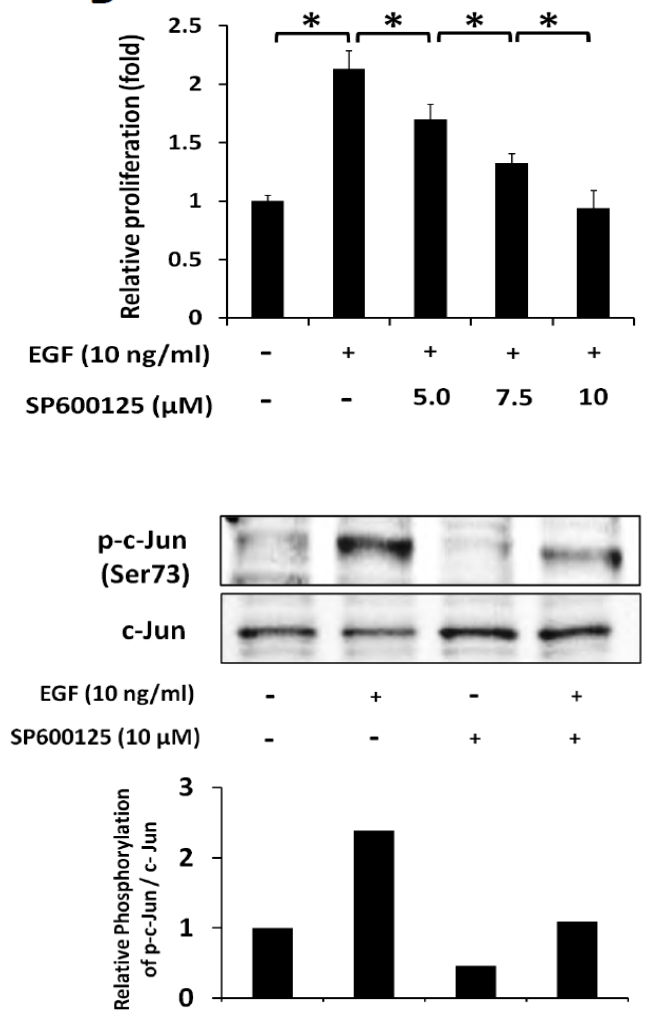

Fig. 2. EGF-induced MEK/ERK- and JNK-mediated signals positively regulate the proliferative activity of PDL-derived EPC-like fibroblastic cells. SCDC2 cells were treated with the (A) MEK inhibitor U0126 or (B) JNK inhibitor SP600125 at the indicated doses for 3 days, as described in Materials and Methods. Then, the WST-1 assay was performed as described in Materials and Methods. Each experiment was repeated 3 times with 6 wells for each point $\left({ }^{*} \mathrm{P}<0.01{ }^{* *} \mathrm{P}<0.05\right)$. (C) Left panels: in order to confirm that U0126 (5 $\mu \mathrm{M})$ properly attenuated the EGF-induced signals at the MEK level, the phosphorylation status of the MEKdownstream molecule ERK was evaluated in EGF-treated SCDC2 cells with or without U0126 by western blotting. Right panels: in order to confirm that the SP600125 (10 $\mu \mathrm{M})$ properly attenuated the EGF-induced JNK-mediated signaling, the phosphorylation status of the JNK-downstream molecule c-Jun with or without SP600125 was evaluated in the EGF-treated SCDC2 cells by western blotting.

$\alpha$-SMA (a) in a dose-dependent manner. In addition, U0126 (5 $\mu \mathrm{M})$ significantly upregulated mRNA expression of h1-calponin (b) and colIa1 (c). Moreover, immunocytochemical analysis revealed that the presence of $5 \mu \mathrm{M}$ U0126 in SCDC2 cell culture under $10 \mathrm{ng} / \mathrm{mL}$ EGF stimulation enhanced $\alpha$-SMA staining (red; Fig. 3B-a). A similar result was observed in the staining of h1-calponin (red; Fig. 3B-b). On the other hand, immunocytochemical studies revealed that U0126 $(5 \mu \mathrm{M})$ did not significantly affect the expression of the EC-specific marker Tie-2 in the EGF-stimulated SCDC2 cells (data not shown). These results suggest that a large population of SCDC2 cells maintain an EC-like character even if EGF-induced MEK/ ERK signaling is inhibited by U0126, implicating that the U0126-induced MF differentiation of the cells might not seem to be mature MF differentiation. Thus, EGF-induced MEK/ERK signaling suppressed MF differentiation of SCDC2 cells. On the contrary, unlike U0126, SP600125 alone (up to $10 \mu \mathrm{M}$ ) did not induce MF differentiation of SCDC2 cells (data not shown). Intriguingly, the JNK inhibitor additively enhanced the MEK inhibitor-induced MF differentiation of the EGF-stimulated cells (Fig. 3C). 


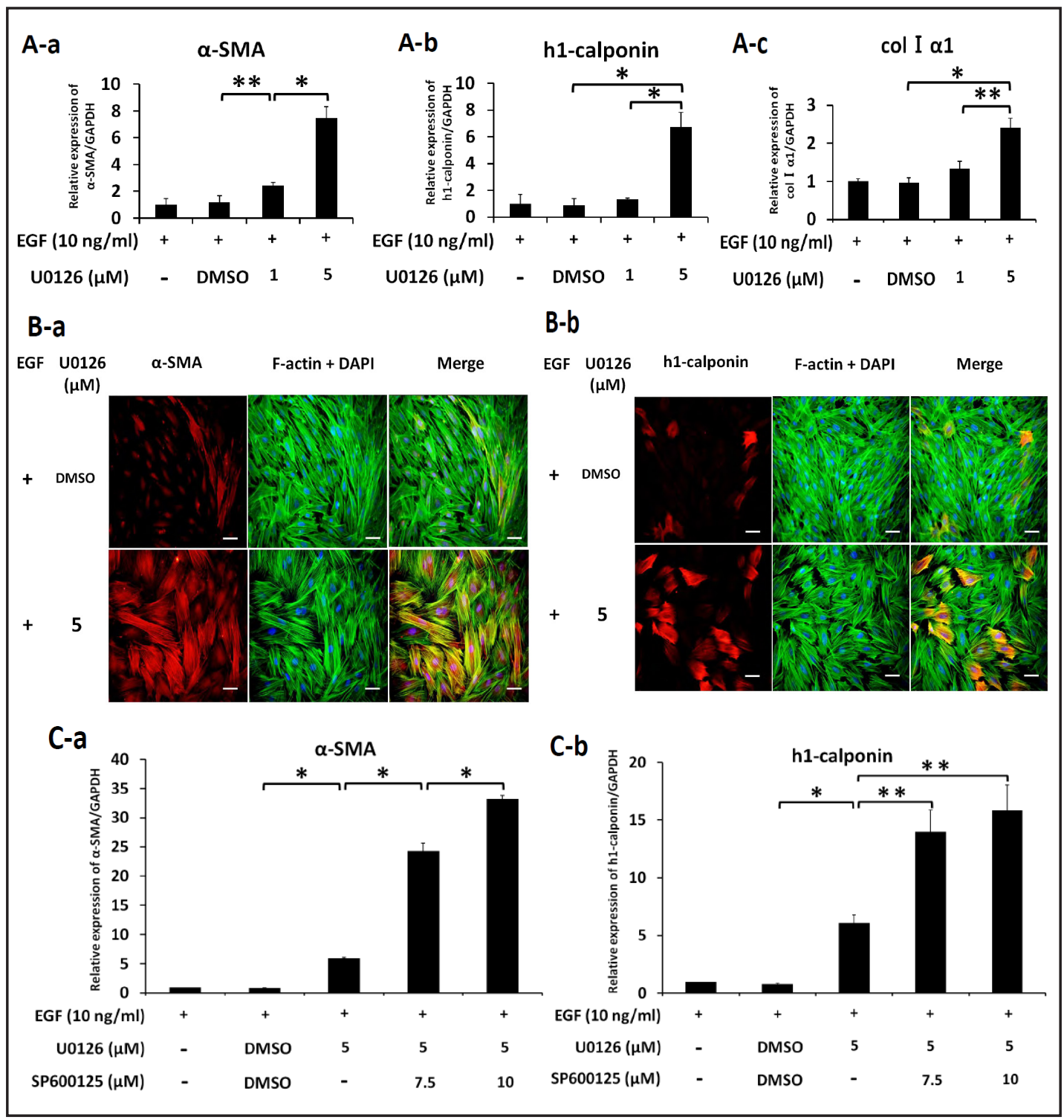

Fig. 3. EGF-induced MEK/ERK-mediated signals negatively regulate MF differentiation of the PDL-derived EPC-like fibroblastic cells. (A) Cells were treated with EGF $(10 \mathrm{ng} / \mathrm{mL})$ with or without MEK inhibitor U0126 (1-5 $\mu \mathrm{M})$ and cultured for 3 days. Then, the total RNA was isolated, and the expression patterns of MF markers (a, $\alpha$-SMA; b, h1-calponin; c, colI $\alpha 1$ ) were evaluated by using qRT-PCR as described in Materials and Methods. The mRNA expression levels of these genes were normalized to those of GAPDH, and the relative expression levels were shown as fold increases or decreases relative to the level in the control. Data are represented as the means \pm SD for 4 dishes for each time point $\left({ }^{*} \mathrm{P}<0.01\right.$; $\left.{ }^{*} \mathrm{P}<0.05\right)$. (B) SCDC2 cells were treated with EGF $(10 \mathrm{ng} / \mathrm{mL})$ with or without U0126 $(5 \mu \mathrm{M})$ and cultured for 3 days. Next, the cells were immunostained with (a) anti- $\alpha$-SMA (red) or (b) anti-h1 calponin (red), and then the cells were labeled with phalloidin (green) and DAPI (blue) as described in Materials and Methods. Scale bar, $50 \mu \mathrm{m}$. (C) Cells were treated with EGF $(10 \mathrm{ng} / \mathrm{mL})$ with or without U0126 (5 $\mu \mathrm{M})$ and JNK inhibitor SP600125 (7.5-10 $\mu \mathrm{M})$ and cultured for 3 days. Then, the expression patterns of MF markers were evaluated as described in (A).

EGF possibly affects fibrous tissue remodeling in mechanical tensile force-loaded PDL by controlling the MF differentiation of the PDL-derived EPC-like fibroblastic cells

Using the tensile force application method against cultured cells on plastic tissue culture plates as described in Materials and Methods, we examined how tensile force affected the 


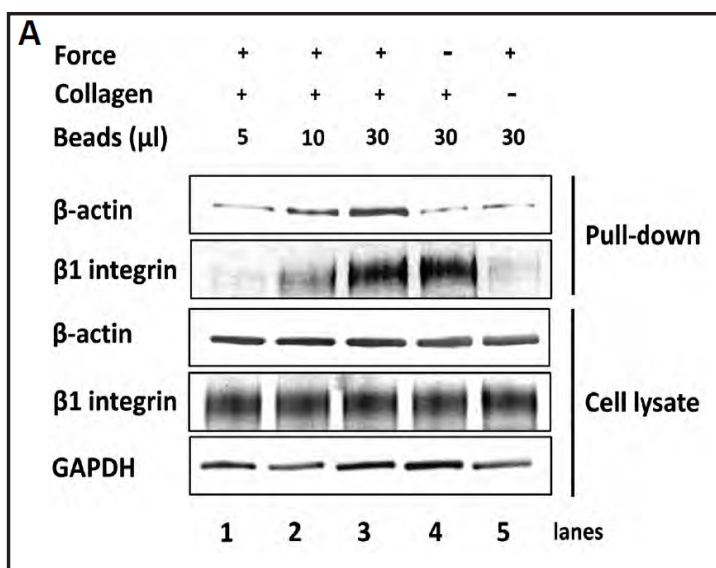

Fig. 4. EGF-induced MEK/ERK-mediated signals suppress the tensile force-induced expression of MF markers but do not suppress the formation of F-actin stress fibers in PDL-derived EPC-like fibroblastic cells. (A) Various numbers of collagen-coated or non-coated magnetite beads were incubated with $5.0 \times 10^{5}$ cells cultured on a plastic tissue culture plate, as described in Materials and Methods. A permanent magnet was used to generate a mechanical force against the beads perpendicular to the dorsal surface of the cell. The magnetic force application against the collagen beads attached to the cell surface was loaded for $60 \mathrm{~min}$. Then, the detection of proteins that were associated with the collagencoated beads was performed as described in Materials and Methods: the bead-associated cytoskeletal proteins indicated as "Pull-down" in upper 2 panels were evaluated by using western blot analyses. The results of immune-detection using "whole cell lysates" are shown in the lower 3 panels. (B) Cells were first incubated with collagen-coated beads (beads in $30 \mu \mathrm{L}$ of stock solution), which attached to dorsal surfaces of cultured cells as described above. Then, tensile force was applied for 3 days with or without EGF $(10 \mathrm{ng} / \mathrm{mL})$ and U0126 (5 $\mu \mathrm{M})$. Next, the mRNA expression level of $\alpha$-SMA was analyzed by using qRT-PCR as described in Materials and Methods. Data represent the mean $\pm \mathrm{SD}$ of experiments conducted in 3 dishes $\left({ }^{*} \mathrm{P}<0.01 ; * * \mathrm{P}<0.05\right)$. (C) Cells were first cultured with or without TGF- $\beta 1(1 \mathrm{ng} /$ $\mathrm{mL})$ for 3 days, then with or without EGF $(10 \mathrm{ng} / \mathrm{mL})$ for 3 days as described in Materials and Methods
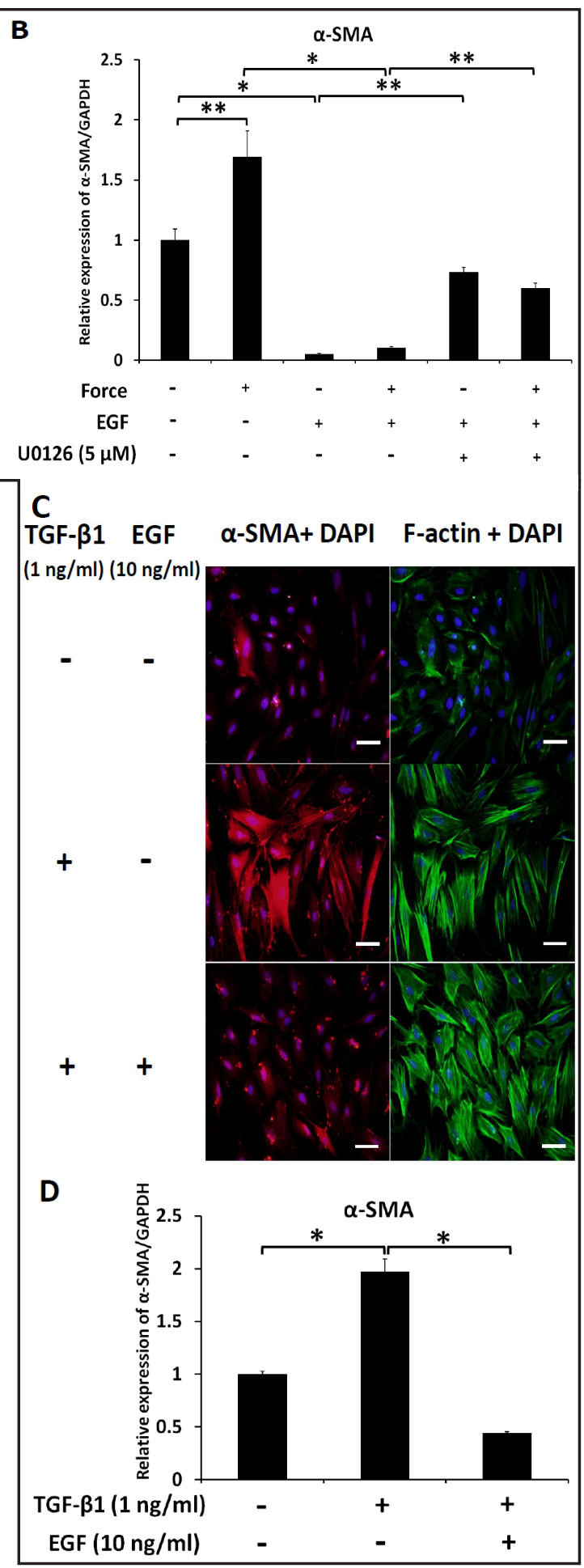

(upper panels, no treatment; middle panels, TGF- $\beta 1$ alone; lower panels, TGF- $\beta 1$ and EGF). Then, the cells were immunostained with anti- $\alpha$-SMA (red; left panels) or phalloidin (green; right panels) as described in Materials and Methods. All the cells were labeled with DAPI (blue). Scale bar, $50 \mu \mathrm{m}$. (D) Cells were treated with TGF- $\beta 1$ or EGF as described in (C). Then, the expression status of $\alpha$-SMA mRNA was evaluated as described in (B). Data represent the means \pm SD of 4 dishes for each point $\left({ }^{*} \mathrm{P}<0.01\right)$.

expression of MF differentiation markers in SCDC2 cells. Chan, et al. previously reported that the tensile force against $\beta 1$ integrin on the cell surface of human gingival fibroblasts induced 


\section{Cellular Physiology Cell Physiol Biochem 2013;32:899-914 and Biochemistry

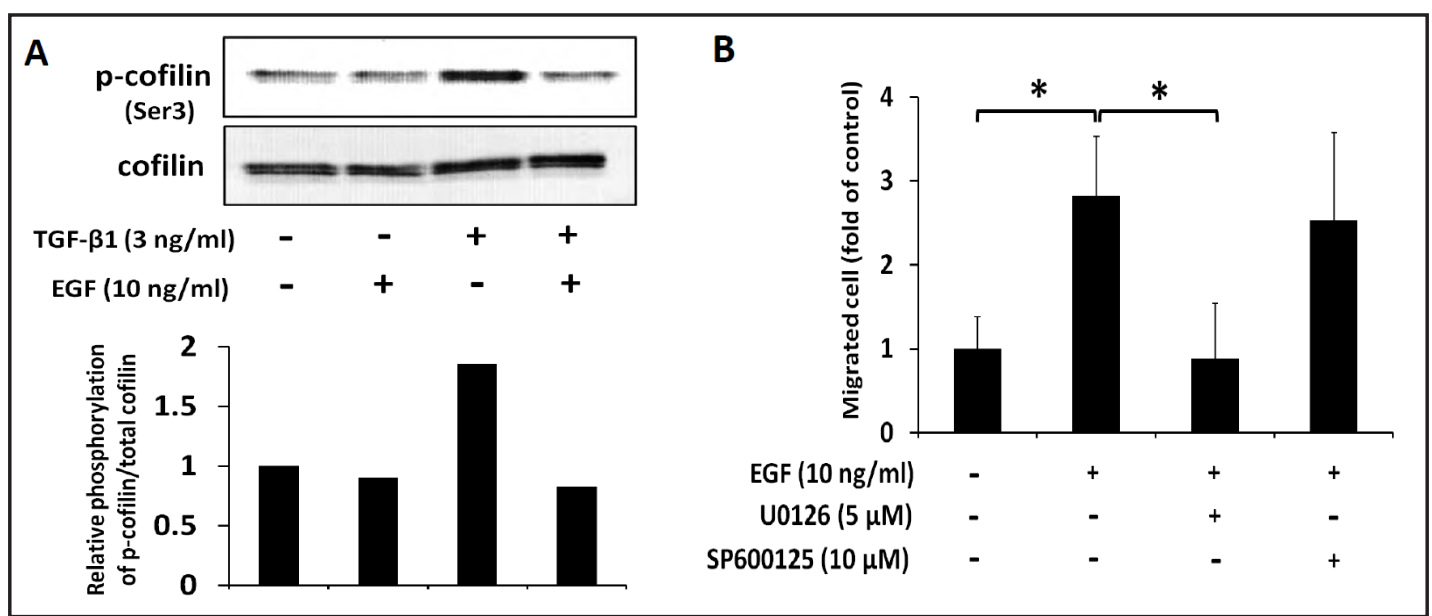

Fig. 5. EGF stimulates migratory activity of SCDC2 cells in a MEK/ERK-dependent manner. (A) Cells were seeded in tissue culture dishes with a basal growth media containing FGF-1 $(10 \mathrm{ng} / \mathrm{mL})$, as described in Materials and Methods and cultured for $22 \mathrm{~h}$. Subsequently, EGF (10 ng/mL) was added to some of the cell culture dishes, which were incubated for $2 \mathrm{~h}$. Next, TGF- $\beta 1$ ( $3 \mathrm{ng} / \mathrm{mL}$ ) was added to some of cell culture dishes, which were then incubated for an additional 30 min (lane 1, no treatment; lane 2, EGF alone; lane 3 , TGF- $\beta 1$ alone; lane 4, EGF and TGF- $\beta 1$ ). Then, phosphorylation of cofilin at Ser3 was evaluated by using western blot analysis, as described in Materials and Methods. (B) The migratory ability of the cells was assessed using a Boyden chamber, as described in Materials and Methods. Data represent the mean \pm SD of experiments conducted in 3 chambers $\left({ }^{*} P<0.05\right)$.

the polymerization of globular actins (G-actins) that anchored to $\beta 1$ integrin, resulting in formation of the integrin-anchored filamentous actin (F-actin), and subsequently induced the expression of MF specific marker $\alpha$-SMA [26]. Firstly, we examined whether such a tensile force against the cell surface could induce F-actin stress fiber formation in SCDC2 cells. As shown in Fig. 4A, a permanent, magnet-generated tensile force against the $\beta 1$ integrin on the surface of SCDC 2 cells, mediated by collagen-coated magnetite beads, clearly increased the amount of bead-integrin-actin complexes in a bead-volume-dependent manner (lanes 1 to 3 of the top 2 panels). In contrast, little or no actin binding to the collagen-coated beadintegrin complexes in the cells was observed in the absence of force application (lane 4 of the top 2 panels). In addition, non-coated beads bound to neither $\beta 1$ integrin nor actin, even if tensile force was applied (lane 5 of the top 2 panels). Moreover, the tensile force or bead application did not alter the protein expression of $\beta$-actin, $\beta 1$ integrin, or GAPDH (bottom 3 panels). These results suggest that the experimental system generating tensile force against $\beta 1$ integrin works as expected: the tensile force against cell surface induces the formation of F-actin stress fibers. We also found that a tensile force against $\beta 1$ integrin on the surface of SCDC2 cells significantly upregulated the expression of the MF marker $\alpha$-SMA (Fig. 4B). Intriguingly, EGF $(10 \mathrm{ng} / \mathrm{mL})$ clearly suppressed the tensile force-induced expression of $\alpha$-SMA, and the suppressive effect of EGF on MF marker expression was partially inhibited by U0126 $(5 \mu \mathrm{M})$.

On the other hand, TGF- $\beta$ has the ability to induce the differentiation of various types of cells into MFs that typically exhibit the formation of F-actin stress fibers [reviewed in 29]. Therefore, we evaluated how EGF affected the TGF- $\beta$-enhanced F-actin stress fiber formation in SCDC2 cells. Immunofluorescence analysis revealed that EGF did not inhibit this effect in SCDC2 cells (green; Fig. 4C, right panels), whereas EGF clearly suppressed TGF- $\beta$-induced $\alpha$-SMA expression in SCDC2 cells (red; Fig. 4C, left panels). The suppressive effect of EGF on the TGF- $\beta$-induced $\alpha$-SMA expression was similarly demonstrated when using the qRT-PCR analysis (Fig. 4D). In addition, EGF alone did not upregulate the expression of $\alpha$-SMA, either at the mRNA or the protein level (data not shown). 
EGF stimulates SCDC2 cell migratory activity in a MEK/ERK-dependent manner

As shown in Fig. 4C, EGF did not inhibit the TGF- $\beta 1$-enhanced stress fiber formation in SCDC2 cells. However, EGF did seem to cause the cell morphology to change from a spreadout shape into a narrow and three-dimensional shape (data not shown), suggesting that EGF is also likely to induce actin cytoskeletal reorganization. First, we evaluated whether EGF affected the phosphorylation of the actin-depolymerizing factor cofilin at Ser3, as the depolymerizing activity of cofilin is negatively controlled by Ser3 phosphorylation [30, 31]. As shown in Fig. 5A, EGF clearly suppressed the TGF- $\beta 1$-induced phosphorylation of cofilin at Ser3, suggesting that EGF possibly affects the status of actin cytoskeletal reorganization. In general, as the actin cytoskeleton is a key determinant of cell shape and motility [reviewed in 32], these findings suggest that EGF might affect the morphology and migratory activity of these cells.

To examine whether EGF affects SCDC2 cell migration, a migration chamber assay was performed, as described in Materials and Methods. As shown in Fig. 5B, EGF (10 ng/mL) significantly stimulated the migratory activity of SCDC2 cells. Intriguingly, U0126 (5 $\mu \mathrm{M})$ significantly suppressed the EGF-induced migratory activity, whereas SP600125 $(10 \mu \mathrm{M})$ did not. In addition, we confirmed that DMSO (the vehicle for the MEK- and JNK-inhibitors) did not affect the migratory activity of the cells (data not shown). These results strongly suggest that EGF stimulates migratory activity through MEK/ERK-mediated signals.

\section{Discussion}

Type I collagen turnover in PDL tissue occurs at rapid rates: in the skin of adult rats, the mean rate lies between 3 to $5 \%$ per day, although rates of more than $10 \%$ a day have been observed in PDLs [reviewed in 33]. Structural and biochemical changes in type I collagen were observed in PDL tissue during the tooth movement through alveolar bone by orthodontic force application: matrix metalloproteinases (MMPs) played important roles on the remodeling of PDL tissue through the degradation of type I collagen, which was one of the main components of fibrous connective tissue in PDL [34]. Intriguingly, MMP-13 (collagenase 3) expression was induced in both the compressed- and tensed-sides of the PDL caused by unidirectional orthodontic force loading on the rat maxillary molars [34]. On the other hand, Nakagawa et al. demonstrated that type I collagen gene expression during orthodontic tooth movement was more pronounced in the tensed-side of rat PDL rather than the compressed-side [35]. These findings suggest that the remodeling of fibrous tissue in the tensile force-loaded PDL seems to be faster than that in the absence of tensile force.

Differentiated MFs exhibit specific characteristics such as an increased production of extracellular matrices (ECMs) involving type I collagen, the development of F-actin stress fibers [9], and the expression of the cell contraction-related molecules $\alpha$-SMA and h1-calponin $[9,36]$. As described above, the expression of $\alpha$-SMA in the tensed-side of PDLs was induced during orthodontic tooth movement in 6-week male rats [10], suggesting that PDL fibroblasts might possess the potential to differentiate into MFs in response to mechanical tensile force loading. Intriguingly, we previously demonstrated elevated expressions of the MF markers $\alpha$-SMA and h1-calponin in the PDL-derived EPC-like SCDC2 cells following stimulation with TGF- $\beta 1$ [8], suggesting that PDL tissue contains progenitor cells of differentiated MFs that can play important roles in remodeling fibrous tissues in PDL by producing ECM molecules such as type I collagen.

In this study, we first demonstrated that EGF stimulated the proliferative activity of PDL-derived EPC-like SCDC2 cells through intracellular signals mediated by EGFR and its downstream signaling molecules MEK/ERK and JNK (Figs. 1 and 2). In contrast, as we previously reported, the FGF-1-induced SCDC2 cell proliferation was mediated via MEK/ ERK but not JNK [37], suggesting that the signal pathways induced by FGF-1 and EGF were partly distinct with respect to their effects on cell proliferation in these cells. 
Next, an important point to note is how cells coordinate proliferation and differentiation during tissue remodeling. In general, growth and proliferation are poorly compatible with differentiation; proliferation/differentiation switches have been demonstrated in different cell types [38-40]. Therefore, we examined whether an MEK inhibitor and a JNK inhibitor, which have been shown to suppress EGF-induced proliferative activity in SCDC2 cells, induced the MF differentiation of EGF-stimulated cells. We found that the MEK inhibitor U0126 $(5 \mu \mathrm{M})$, which completely suppressed the EGF-induced upregulation of proliferative activity in these cells (Fig. 2A), clearly induced the expression of the MF differentiation markers $\alpha$-SMA, h1-calponin, and coll $\alpha 1$ (Fig. 3A, B, and C), strongly suggesting that EGF attenuates MF differentiation through a MEK/ERK-dependent signal. In contrast, the JNK inhibitor SP600125 $(10 \mu \mathrm{M})$ alone did not affect MF marker expression in these cells (data not shown), even if SP600125 $(10 \mu \mathrm{M})$ alone totally suppressed the EGF-induced proliferation of SCDC2 cells (Fig. 2B). Thus, growth inhibition by a JNK inhibitor does not seem to be sufficient to induce the expression of MF differentiation markers. Intriguingly, the JNK inhibitor enhanced the MEK inhibitor-induced MF differentiation of the cells (Fig. 3C-a and -b), suggesting that JNK-mediated signals may negatively affect MF differentiation status only when the MEK/ERK activity is suppressed. These findings suggest a unique JNK- and MEK/ERK-pathway crosstalk during the MF differentiation of the PDL-derived EPC-like cells.

Chan et al. demonstrated that the tensile force against $\beta 1$ integrin on the cell surface of HGFs induced both F-actin stress fiber formation and the subsequent upregulation of MF marker expression [26]. On the other hand, Meng et al., by using a culture plate that could be bent with a uniaxial four-point mechanical stress, demonstrated that mechanical tension stress induced $\alpha$-SMA expression in cultured human PDL fibroblasts [41]. However, they did not elucidate the molecular mechanisms underlying the tensile force-induced expression of $\alpha$-SMA in the cells. In addition, they did not investigate how the tensile force affected the F-actin stress fiber formation in the PDL-derived cells. In this study, we demonstrated that the tensile force mediated by $\beta 1$ integrin clearly induced integrin-anchored actin-polymerization in PDL-derived EPC-like fibroblasts (Fig. 4A). Intriguingly, EGF significantly inhibited the tensile force-induced $\alpha$-SMA mRNA expression in a MEK/ERK-dependent manner (Fig. 4B).

Cofilin is an actin-binding protein that works as a key molecule for actin filament reorganization by depolymerizing F-actin stress fibers, resulting in cell shape change or cell migratory activity [reviewed in 42,43 ]. Cofilin activity is negatively regulated by phosphorylation at Ser3. As shown in Fig. 5A, EGF was able to decrease the TGF- $\beta 1$-induced phosphorylation of cofilin at Ser3 in SCDC2 cells, suggesting that EGF possibly stimulates the cofilin-mediated migration of the cells. Therefore, we examined whether EGF could affect the cytoskeletal reorganization and migratory activity of SCDC2 cells and found that EGF significantly activated the cell migratory activity through MEK/ERK-mediated signal (Fig. 5B). Xie et al. previously demonstrated that EGF activated both the proliferative and migratory activities of mouse fibroblast NR6 cells, which were derived from mouse embryonic fibroblast Swiss 3 T3 cells, in a MEK/ERK-dependent manner [44]. Similarly, here we demonstrated that EGF activated both the proliferative and migratory activities of SCDC2 cells in a MEK/ERKdependent manner (Figs. 1,2, and 5). Taken together, EGF appears to promote the proliferation and migration of mesenchymal cells in a MEK/ERK-dependent manner. Intriguingly, Pho et $a l$. previously reported that the level of cofilin phosphorylation at Ser3 was increased during MF differentiation of cells derived from porcine aortic cardiac valves [45], suggesting that phosphorylated cofilin seems to be a characteristic of MF differentiation. As shown in Fig. $5 \mathrm{~A}$, we demonstrated that the TGF- $\beta 1$-induced upregulation of cofilin phosphorylation was suppressed by EGF in SCDC2 cells. In addition, EGF significantly inhibited the tensile forceand TGF- $\beta$-induced MF differentiation of the cells (Fig. 4). Thus, our finding that EGF inhibits both cofilin phosphorylation and MF differentiation is compatible with the report from Pho et al. that MFs have a much greater ratio of phosphorylated cofilin to non-phosphorylated cofilin than undifferentiated premyofibroblasts.

In general, the abilities of stem/progenitor cells to proliferate, migrate, and differentiate into specialized cells are essential for tissue remodeling and regeneration. Here, we 
demonstrated that EGF induced the proliferative activity of the PDL-derived EPC-like cells in a MEK/ERK- and JNK-dependent manner. In addition, EGF promoted cell migration in a MEK/ERK-dependent manner. Moreover, EGF suppressed the MF differentiation of the cells in a MEK/ERK-dependent manner. These findings are helpful in understanding the cellular and molecular mechanisms underlying the remodeling or regeneration of ligament tissue during tooth movement by orthodontic treatment.

\section{Conflict of Interest}

All authors are in agreement with the content of this manuscript. The authors declare no conflict of interest.

\section{Acknowledgements}

This work was supported in part by Grants-in-Aid for Scientific Research [grant nos. 22791935 and 24792149 (to N.O.), 23592896 (to A.I.), 22592076 (to M.K.), and 25463053 (to N.C.)] of the Ministry of Education, Culture, Sports, Science, and Technology of Japan; the Open Research Project and High-Tech Research Project of the Ministry of Education, Culture, Sports, Science, and Technology of Japan; Grant-in-Aid for Strategic Medical Science Research Center from the Ministry of Education, Culture, Sports, Science, and Technology of Japan, 2010-2014; and the Keiryokai Research Foundation [grant nos. 100 (to N.C.), 2008, and 106 (to A.I.), 2009].

\section{References}

1 Hou LT, Yaeger JA: Cloning and characterization of human gingival and periodontal ligament fibroblasts. J Periodontol 1993;64:1209-1218.

2 Pitaru S, Pritzki A, Bar-Kana I, Grosskopf A, Savion N, Narayanan AS: Bone morphogenetic protein 2 induces the expression of cementum attachment protein in human periodontal ligament clones. Connect Tissue Res 2002;43:257-264.

- 3 Nakamura T, Yamamoto M, Tamura M, Izumi Y: Effects of growth/differentiation factor-5 on human periodontal ligament cells. J Periodontal Res 2003;38:597-605.

- 4 Trubiani O, Isgro A, Zini N, Antonucci I, Aiuti F, Di Primio R, Nanci A, Caputi S, Paganelli R: Functional interleukin-7/interleukin-7Ralpha, and SDF-1alpha/CXCR4 are expressed by human periodontal ligament derived mesenchymal stem cells. J Cell Physiol 2008;214:706-713.

5 Shi S, Bartold PM, Miura M, Seo BM, Robey PG, Gronthos S: The efficacy of mesenchymal stem cells to regenerate and repair dental structures. Orthod Craniofac Res 2005;8:191-199.

6 Seo BM, Miura M, Gronthos S, Bartold PM, Batouli S, Brahim J, Young M, Robey PG, Wang CY, Shi S: Investigation of multipotent postnatal stem cells from human periodontal ligament. Lancet 2004;364:149155.

7 Okubo N, Ishisaki A, Iizuka T, Tamura M: Vascular cell-like potential of undifferentiated ligament fibroblasts to construct vascular cell-specific marker-positive blood vessel structures in a PI3K-activation-dependent manner. J Vasc Res 2010;47:369-383.

8 Yoshida M, Okubo N, Chosa N, Hasegawa T, Ibi M, Kamo M, Kyakumoto S, Ishisaki A: TGF- $\beta$-operated growth inhibition and translineage commitment into smooth muscle cells of periodontal ligament-derived endothelial progenitor cells through Smad- and p38 MAPK-dependent signals. Int J Biol Sci 2012;8:10621074.

-9 Hinz B, Phan SH, Thannickal VJ, Galli A, Bochaton-Piallat M-L, Gabbiani G: Biological perspectives, the myofibroblast, one function, multiple origins. Am J Pathol 2007;170:1807-1816.

10 Meng Y, Han X, Huang L, Bai D, Yu H, He Y, Jing Y: Orthodontic mechanical tension effects on the myofibroblast expression of alpha-smooth muscle actin. Angle Orthod 2010;80:912-918. 


\section{Cellular Physiology $\quad$ Cell Physiol Biochem 2013;32:899-914 and Biochemistry \begin{tabular}{l|l} 
DOI: 10.1159/000354493 & Published online: September 27, 2013 \\
\cline { 2 - 2 }
\end{tabular} \\ Kimura et al.: Effects of EGF on Proliferation, Migration, and Differentiation of Ligament Cells}

11 Cohen S, Elliott GA: The stimulation of epidermal keratinization by a protein isolated from the submaxillary gland of the mouse. J Invest Dermatol 1963;40:1-5.

12 Carpenter G, Cohen S: Epidermal growth factor. Ann Rev Biochem 1979;48:193-216.

13 Wells A: EGF receptor. Int J Biochem Cell Biol 1999;6:637-643.

14 Wang YN, Hung M-C: Nuclear functions and subcellular trafficking mechanisms of the epidermal growth factor receptor family. Cell Biosci 2012;2:13.

15 Citri A, Yarden Y: EGF-ERBB signalling: towards the systems level. Nat Rev Mol Cell Biol 2006; 7:505-516.

16 Dawnward J, Waterfield MD, Parker PJ: Autophosphorylation and protein kinase C phosphorylation of the epidermal growth factor receptor. Effect on tyrosine kinase activity and ligand binding affinity. J Biol Chem 1985;260:14538-14546.

17 Helin K, Velu T, Martin P, Vass WC, Allevato G, Lowy DR, Beguinot L: The biological activity of the human epidermal growth factor receptor is positively regulated by its C-terminal tyrosines. Oncogene 1991;6:825832.

18 Tamama K, Fan VH, Griffith LG, Blair HC, Wells A: Epidermal growth factor as a candidate for ex vivo expansion of bone marrow-derived mesenchymal stem cells. Stem Cells 2006;24:686-695.

- 19 Trubiani O, Zalzal SF, Paganelli R, Marchisio M, Giancola R, Pizzicannella J, Büring HJ, Piattelli M, Caputi S, Nanci A: Expression profile of the embryonic markers nanog, OCT-4, SSEA-1, SSEA-4, and frizzled-9 receptor in human periodontal ligament mesenchymal stem cells. J Cell Physiol 2010;225:123-131.

20 Matsuda N, Yokoyama K, Takeshita S, Watanabe M: Role of epidermal growth factor and its receptor in mechanical stress-induced differentiation of human periodontal ligament cells in vitro. Arch Oral Biol 1998;43:987-997.

21 Kong K, Majeska RJ, Vazquez M: Migration of connective tissue-derived cells is mediated by ultra-low concentration gradient fields of EGF. Exp Cell Res 2011;317:1491-1502.

22 Osaki LH, Gama P: MAPKs and signal transduction in the control of gastrointestinal epithelial cell proliferation and differentiation. Int J Mol Sci 2013;14:10143-10161.

23 Krens SF, Spaink HP, Snaar-Jagalska BE: Functions of the MAPK family in vertebrate-development. FEBS lett 2006;580:4984-4990.

24 Harmer NJ: Insights into the role of heparan sulfate in fibroblast growth factor signaling. Biochem Soc Trans 2006;34:442-445.

25 Glogauer M, Arora P, Chou D, Janmey PA, Downey GP, McCulloch CA: The role of actin-binding protein 280 in integrin-dependent mechanoprotection. J Biol Chem 1998;273:1689-1698.

26 Chan MW, Chaudary F, Lee W, Copeland JW, McCulloch CA: Force-induced myofibroblast differentiation through collagen receptors is dependent on mammalian diaphanous (mDia). J Biol Chem 2010;285:92739281.

27 Glogauer M, Ferrier J, McCulloch CA: Magnetic fields applied to collagen-coated ferric oxide beads induce stretch-activated $\mathrm{Ca}^{2+}$ flux in fibroblasts. Am J Physiol 1995;269:C1093-1104.

28 Bridges AJ, Zhou H, Cody DR, Rewcastle GW, McMichael A, Showalter HD, Fry DW, Kraker AJ, Denny WA: Tyrosine kinase inhibitors. 8. An unusually steep structure-activity relationship for analogues of 4-(3-bromoanilino)-6,7-dimethoxyquinazoline (PD 153035), a potent inhibitor of the epidermal growth factor receptor. J Med Chem 1996;39:267-276.

29 Snadbo N, Dulin N: Actin cytoskeleton in myofibroblast differentiation: ultrastructure defining form and driving function. Transl Res 2011;158:181-196.

30 Moriyama K, Iida K, Yahara I: Phosphorylation of Ser-3 of cofilin regulates its function on actin. Genes Cells 1996;1:73-86.

31 Nagaoka R, Abe H, Obinata T: Site-directed mutagenesis of the phosphorylation site of cofilin: its role in cofilin-actin interaction and cytoplasmic localization. Cell Motil Cytoskeleton 1996;35:200-209.

-32 Stricker J, Falzone T, Gardel ML: Mechanics of the F-actin cytoskeleton. J Biomech 2010;43:9-14.

33 Laurent GJ: Dynamic state of collagen: pathways of collagen degradation in vivo and their possible role in regulation of collagen mass. Am J Physiol Cell Physiol 1987;252:C1-9.

-34 Leonardi R, Talic NF, Loreto C: MMP-13 (collagenase 3) immunolocalization during initial orthodontic tooth movement. Acta Histochem 2007;109:215-220.

35 Nakagawa M, Kukita T, Nakasima A, Kurisu K: Expression of the type I collagen gene in rat periodontal ligament during tooth movement as revealed by in situ hybridization. Arch Oral Biol 1994;39:289-294. 


\section{Cellular Physiology $\quad$ Cell Physiol Biochem 2013;32:899-914 and Biochemistry \\ Kimura et al.: Effects of EGF on Proliferation, Migration, and Differentiation of Ligament Cells}

-36 Forte A, Corte AD, Feo MD, Cerasuolo F, Cipollaro M: Role of myofibroblasts in vascular remodelling: focus on restenosis and aneurysm. Cardiovasc Res 2010;88:395-405.

37 Takahashi M, Okubo N, Chosa N, Takahashi N, Ibi M, Kamo M, Mizuki H, Ishisaki A, Kyakumoto M: Fibroblast growth factor-1-induced ERK1/2 signaling reciprocally regulates proliferation and smooth muscle cell differentiation of ligament-derived endothelial progenitor cell-like cells. Int. J Mol Med 2012;29:357-364.

-38 Chen JF, Mandel EM, Thomson JM, Wu Q Callis TE, Hammond SM, Conlon FL, Wang DZ: The role of microRNA-1 and microRNA-133 in skeletal muscle proliferation and differentiation. Nat Genet 2006;38:228-233.

39 Conti L, Sipione S, Magrassi L, Bonfanti L, Rigamonti D, Pettirossi V, Peschanski M, Haddad B, Pelicci P, Milanesi G, Pelicci G, Cattaneo E: Shc signaling in differentiating neural progenitor cells. Nat Neurosci 2001;4:579-586.

40 Dugan LL, Kim JS, Zhang Y, Bart RD, Sun Y, Holtzman DM, Gutman DH: Differential effects of cAMP in neurons and astrocytes. Role of B-raf. J Biol Chem 1999;274:25842-25848.

41 Meng Y, Han X, Huang L, Bai D, Yu H, He Y, Jing Y: Orthodontic mechanical tension effects on the myofibroblast expression of alpha-smooth muscle actin. Angle Orthod 2010;80:912-918.

42 Ono S: Mechanism of depolymerization and severing of actin filaments and its significance in cytoskeletal dynamics. Int Rev Cytol 2007;258:1-82.

43 Mizuno K: Signaling mechanisms and functional roles of cofilin phosphorylation and dephosphorylation. Cell Signal 2013;25:457-469.

-44 Xie H, Pallero MA, Gupta K, Chang P, Ware MF, Witke W, Kwiatkowski DJ, Lauffenburger DA, MurphyUllrich JE, Wells A: EGF receptor regulation of cell motility: EGF induces disassembly of focal adhesions independently of the motility-associated PLCgamma signalling pathway. J Cell Sci 1998;111:615-624.

45 Pho M, Lee W, Watt DR, Laschinger C, Simmons CA, McCulloch CA: Cofilin is a marker of myofibroblast differentiation in cells from porcine aortic cardiac valves. Am J Physiol Heart Circ Physiol 2008;294:H17671778. 